\title{
High-speed rail system in China: best practice, state of affairs and prospects for development
}

\author{
Dmitry Kuzmin ${ }^{1, *}$, Vera Baginova ${ }^{1}$, and Andrey Baginov ${ }^{1}$ \\ ${ }^{1}$ Russian University of Transport RUT (MIIT), Obrazcova Street, 9b9, 127994, Moscow, Russia
}

\begin{abstract}
The article analyzes the experience of organizing high-speed rail services in China, the current state and development prospects. An analysis of open sources and publications on this topic is carried out. The characteristics of the infrastructural support of the most significant transport facilities of high-speed rail transportation are given and the question of further development of high-speed rail service in People's Republic of China is considered. An assessment is made of the economic and social significance of China's high-speed railway lines.
\end{abstract}

\section{Introduction}

Rail transport is one of the key industries in China. The development of railway service directly determines the degree of territorial integrity of the country, uniting all administrative units (provinces and autonomous districts), and also provides international link with neighboring states. The large population (over 1.395 billion people - the first place in the world) and large territories (9.5 million $\mathrm{km}^{2}$ - the third place in the world) determine the particular relevance of the development of railway transport infrastructure.

The modern railway system of China is in continuous development and is one of the largest in the world (2nd place in the world in terms of the total length of the public railway network). As of 2018, the passenger turnover on the railway transport amounted to $1,414,658$ million pass* $\mathrm{km}$, which is $5.1 \%$ more than in the previous year, and the cargo turnover $-2,882,099$ million $\mathrm{t}^{*} \mathrm{~km}$, exceeding the previous year's figures by $6.9 \%$ [3]. Also, rail transport plays a key role in the economic development of the western regions of China, which have a lower socio-economic profile.

\footnotetext{
* Corresponding author: kuzminmiit@gmail.com
} 


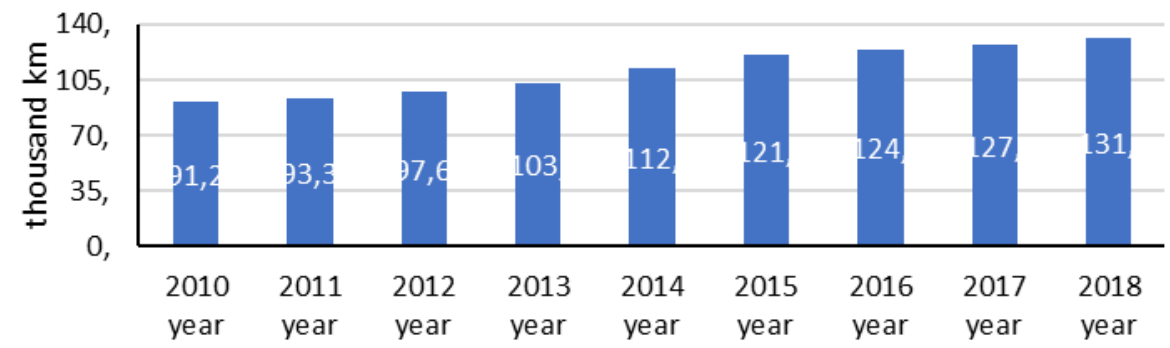

Fig. 1. The total length of China's railways.

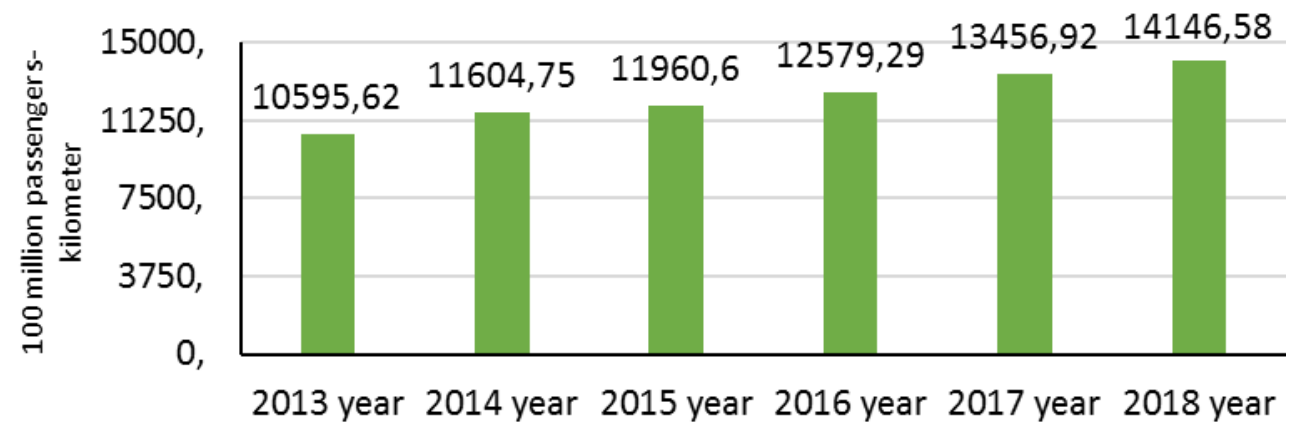

Fig. 2. Passenger turnover throughout People's Republic of China by railway transport.

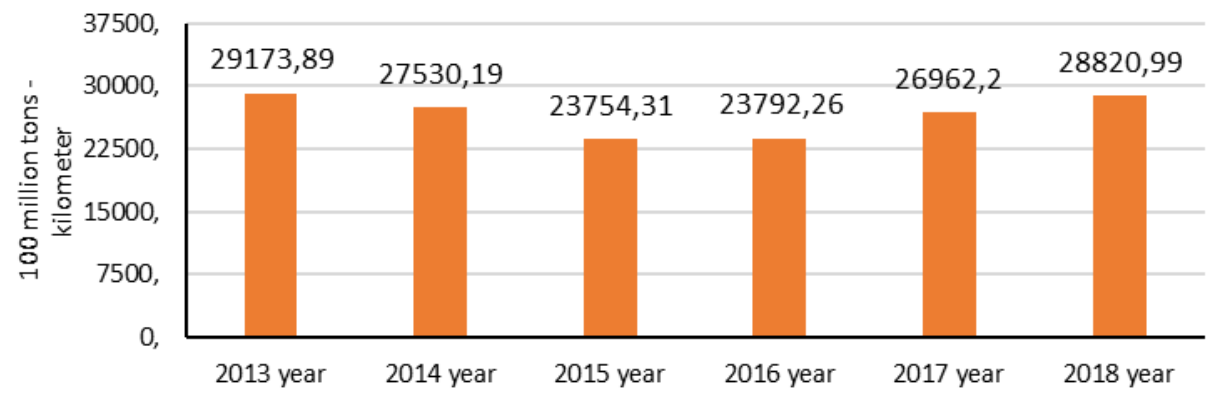

Fig. 3. Cargo turnover throughout People's Republic of China by railway transport.

Nowadays, special attention is paid by the Chinese government to the development of high-speed rail services. As of 2018, the total length of high-speed railway lines was more than 29 thousand $\mathrm{km}$ [4]. The most active pace of development of the Chinese high-speed railway lines fell on the 11th and 12th five-year plans (2006-2015). (Figure 4) [2]. Today, the Chinese high-speed transportation infrastructure is the largest in the world - 30 thousand $\mathrm{km}$, which is $67 \%$ of the global length of high-speed railway lines. 


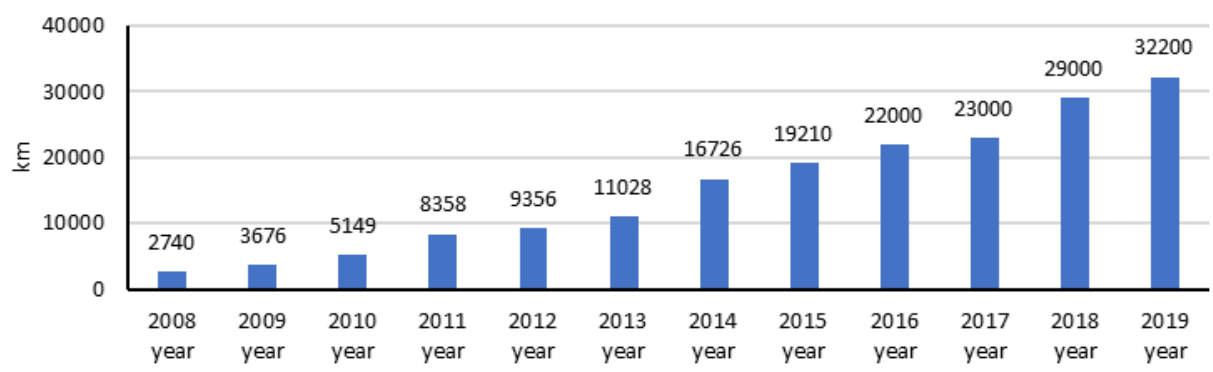

Fig. 4. Operational length of the Chinese high-speed railway lines.

The main part of the Chinese high-speed railway lines is located in the eastern part. This is due to several reasons: firstly, the number of people in the eastern regions and, as a consequence, the desire to increase labor migration and business activity in these regions, and secondly, the geographical characteristics of the east of the country.

In fact, the history of the development of high-speed service in China began in 2008 with the development of a government plan - the development program "Four Verticals and Four Horizontals" (四纵四横, 4+4):

Geography of the planned verticals:

1. Beijing - Wuhan - Guangzhou - Shenzhen (Hong Kong);

2. Beijing - Tianjin - Nanjing - Shanghai;

3. Beijing - Shenyang - Harbin (Dalian);

4. Shanghai - Hangzhou - Ningbo - Fuzhou - Shenzhen.

Geography of the planned contours:

1. Xuizhou - Zhengzhou - Xi'an - Lanzhou;

2. Shanghai - Hangzhou - Nanchang - Changsha - Kunming;

3. Qingdao - Shijiazhuang - Taiyuan;

4. Shanghai - Nanjing - Hefei - Zhongqing - Chengdu.

Seven years later, this program was implemented, and in 2016 it got its continuation and formed the basis of the plan - the program "Eight Verticals and Eight Horizontals" (八纵八横, 8+8), with a planned implementation period by 2030 .

At present, the Guangxi Zhuang Autonomous Region (广西壮族自治区) has the longest network of high-speed railway lines $(1,751 \mathrm{~km})$, the administrative center is the city of Nanning (南宁). The second place (1,542 km) is occupied by Guangdong (广东) province, the administrative center is located in Guangzhou (广州). In third place $(1,500$ $\mathrm{km}$ ) is Fujian (福建) province with the administrative center in Fuzhou (福州). The ranking of the most developed provinces in the aspect of the Chinese high-speed railway line infrastructure is presented in Figure 5. 


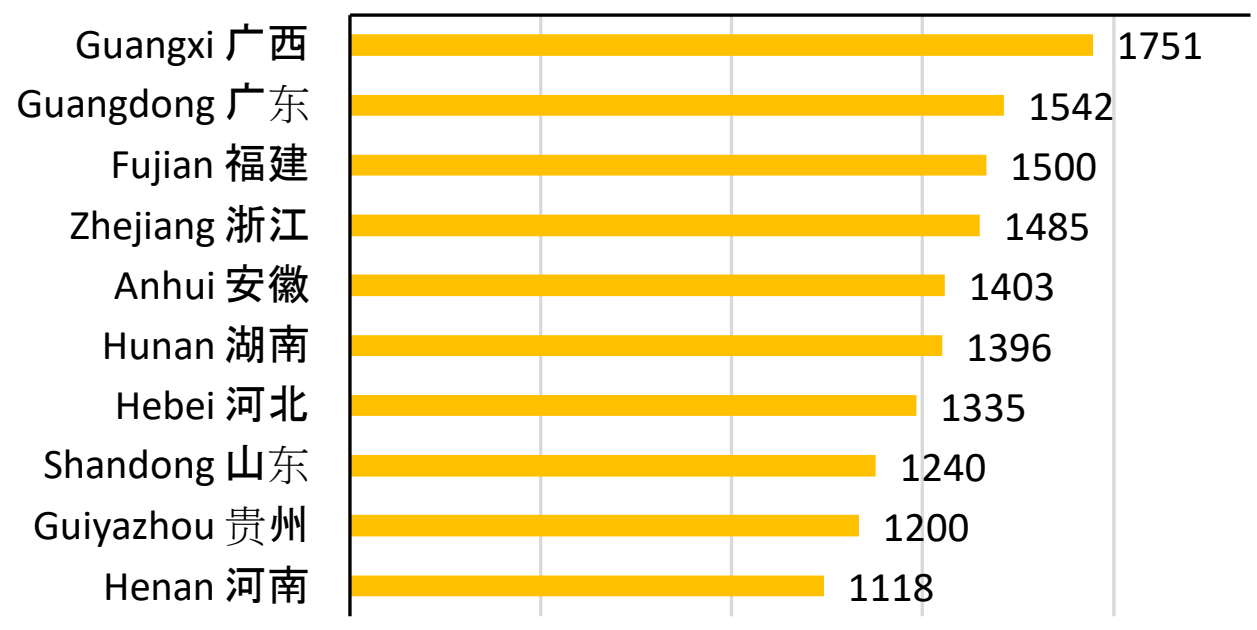

Fig. 5. 10 provinces of People's Republic of China with the longest high-speed railway lines, $\mathrm{km}$ (2018).

The infrastructure of high-speed railway transport developed comprehensively and implied not only the construction of link lines, but also the modernization of transport hubs, which suggested high standards of passenger service. At present, the passenger infrastructure of China's high-speed railway lines has the following large stations [6]:

1. Northern Xi'an Station (西安北站): 18 platforms (2 side platforms, 16 island platforms, was put into operation on January 11, 2011).

2. Zhengzhou East Station (郑州东站): 16 platforms (2 side platforms, 14 island platforms, was put into operation on September 28, 2012).

3. Kunming South Station (昆明南站): 16 platforms (2 side platforms, 14 island platforms, was put into operation on December 28, 2016).

4. Shanghai Hongqiao Station (上海虹桥站): 16 platforms (2 side platforms, 14 island platforms, was put into operation on July 1, 2010).

5. Chongqing North Station (重庆西站): 15 platforms (1 side platform, 14 island platforms, was put into operation on January 25, 2018).

The construction of passenger transport hubs in China's high-speed railway lines has its own specifics.

First, preference is given to special economic zones that are not overloaded with infrastructure. This is due to the desire of the People's Republic of China government to give an impetus to the development of economically weak regions and reduce the burden on modern congested city agglomerations;

Secondly, the characteristic of the new station complexes. A large number of platforms and tracks, significant areas of passenger buildings with a high level of service, high artistic, architectural and aesthetic components;

Thirdly, high safety standards for the operation of station complexes, for example, the use of remote face recognition systems.

Fourth, the use of various solutions to organize work at various levels. A large number of railway stations are built above the ground on various supports.

The largest railway transport hubs are [5]: Beijing, Zheng-zhou, Hefei, Stan, Shanghai, Guangzhou, Changsha, Nanjing, Chongqing, Tianjin. 
The most common train model is 《和谐号列车》-《Harmony». The average train speed is about $200 \mathrm{~km} / \mathrm{h}$, and the maximum can reach $350 \mathrm{~km} / \mathrm{h}$. The most modern train is 《复兴号列车》 - 《Renaissance». Depending on the model, this train can move at speeds of $160 \mathrm{~km} / \mathrm{h}, 250 \mathrm{~km} / \mathrm{h}$ or $350 \mathrm{~km} / \mathrm{h}$.

At the dawn of the development of high-speed service in China, there were two large engineering corporations: CSR (China South Locomotive \& Rolling Stock Corp., Ltd.) and CNR (China Northern Locomotive \& Rolling Stock Industry (Group) Corporation), which produced railway trains and locomotives for high-speed railway lines. Starting in 2013, they constantly occupied leading positions in the world in terms of production of highspeed locomotives and rolling stock, and since 2017, sales volumes exceeded the main Western and Asian manufacturers of such products (Bombardier, Alstom, Siemens and Kawasaki). In order to strengthen the position of Chinese products in the global engineering market in this area, in 2017, the People's Republic of China government decided to merge the two companies and create a single corporation - CRRC (China Railway Rolling Stock Corporation). The united corporation has become the largest in the world in the production of rolling stock for railway transport.

The current stage of development of China's high-speed railway lines includes the development of the following four areas:

1. The central direction. China (Urumqi) - Kyrgyzstan, Kazakhstan, Uzbekistan, Turkmenistan, Iran, Turkey and other countries to Germany;

2. East Asian direction. People's Republic of China (Kunming), then through Vietnam, Cambodia, Thailand, Malaysia and to Singapore;

3. The Russian direction. People's Republic of China (Harbin) - Russia - countries of Eastern Europe;

4. Pakistani direction. From Urumqi, the road will go to the Persian Gulf.

The development of high-speed railway service in China has a significant positive effect for the country, namely:

- it is a driver of regional development. The economy of the districts along which the high-speed railway lines pass shows significant growth. Thus, the Beijing - Guangzhou highway combines the 5 most important economic zones of the People's Republic of China into a common economic territory, which leads to increased business activity. For example, after the introduction of high-speed railway lines, the growth of business activity in the 28 largest cities of this economic territory for 5 years will provide additional growth of the country's GDP by $3-4 \%$;

- high-speed railway lines contribute to the development of remote and sparsely populated areas. Thus, the Qinghai - Tibet high-speed railway line ensured 10 years of annual growth in the GDP of the Tibet Autonomous Region by $10 \%$;

- reorientation of passenger flows. The development of high-speed railway lines allows not only unloading ordinary railway lines, but also reducing the load on inter-regional highspeed highways. Due to the fact that in China today there are big environmental problems, the state is carefully trying to reduce the amount of carbon dioxide emissions into the atmosphere. According to the estimates of Chinese economists, the appearance of highspeed railway trains on any route reduces the number of air passengers on the same route by $30 \%$, and the passenger turnover of some regional airlines almost halved. This is due to the fact that the prices for a high-speed train are lower than a plane ticket, and, in most cases, there is no need to travel far outside the city to the airport, since they are mainly located far from the city. In turn, the stations are located in the immediate vicinity or within the city.

Thus, high-speed railway lines play an important role in the Chinese economy. In turn, the People's Republic of China government is making big plans to build high-speed railway 
lines not only on the territory of China itself, but also to organize international service between neighboring states and bring them to Europe.

\section{References}

1. UIC - International union of railways (2019) DOI: https://uic.org/

2. S.L. Sozonov, Z. Wu, Railway transport of the People's Republic of China: development imperatives: monograph, 408, IFES RAS (2019)

3. Statistical summary of railway communication for 2018 (2019) DOI: http:/www.mot.gov.cn/tongjishuju/tielu/

4. High-speed railways in China (2019) DOI: https://baike.baidu.com

5. The rating of urban nodes of high-speed railways in China (2019) DOI: http://mapi.masok.cn/wap/thread/view-thread/tid/3893699

6. Railway stations for high-speed trains (2019) DOI: https://baike.baidu.com/item/\%E9\%AB\%98\%E9\%93\%81\%E7\%AB\%99/20590890?fr $=$ aladdin

7. Planning for China High Speed Rail (2019) DOI: http://cn.gaotie.cn/ 